Какоткина Елена Александровна

соискатель кафедры социологии и управления Белгородского государственного технологического университета имени В.Г. Шухова

\section{ПРИНЦИПЫ ФОРМИРОВАНИЯ СТРАТЕГИИ РАЗВИТИЯ РЕГИОНАЛЬНЫХ ВУЗОВ В КОНТЕКСТЕ НОВЫХ ОРИЕНТИРОВ ВЫСШЕГО ОБРАЗОВАНИЯ}

\section{Аннотация:}

В статье обоснованы принципы разработки стратегии развития региональных вузов в контексте новых ориентиров высшего образования. Среди ключевых из них следует выделить принципы непрерывного образования, региональных приоритетов, клиентоориентированности, опережающего развития, системности, а также отраслевой, региональный и проблемно ориентированный. Соблюдение этих принципов позволит обеспечить подготовку специалистов высокой квалификации в соответствии с требованиями региональной политики; удовлетворение потребностей регионов и профильных отраслей экономики в кадрах; диалог c потребителями образовательных услуг в сфере высшего образования; опережающее развитие системы высшего образования как фактор ускоренного развития территории; проблемно ориентированный подход к разработке и реализации стратегии совершенствования региональных учебных заведений; их оптимальное функционирование как системы в единстве ее подсистем. Внимание ак центировано на системной стратегии формирования имиджа регионального вуза, в котором выделены и рассмотрены ценностная, когнитивная нормативная, целевая, символическая и мотивационная подсистемы.

Ключевые слова

высшее образование, региональный вуз, стратегия развития, принцип.

\section{Kakotkina Elena Aleksandrovna}

External PhD student Sociology and Management Department, Shukhov Belgorod State Technological University

\section{THE PRINCIPLES OF THE DEVELOPMENT STRATEGY FOR REGIONAL UNIVERSITIES IN THE CONTEXT OF THE NEW HIGHER EDUCATION FOCUS}

\section{Summary:}

The research substantiates the principles of the development strategy designed for regional universities in terms of the new focus of higher education. The key ones include the principles of continuing education, regional priorities, advanced development, customercentered, system-based as well as sectoral, regional, and problem-based approaches. Adherence to these principles makes it possible to train highly skilled specialists in accordance with the requirements of regional policy; meet the needs of regions and relevant economic sectors for staff; hold a dialog with higher education service consumers; guarantee the priority development of the higher education system as a factor in the accelerated development of the territory; take a problem-based approach to the strategy for improving regional educational institutions; provide their optimal functioning as a single system with its subsystems. The emphasis is placed on the system-based strategy for creating the image of a regional university which consists of value, cognitive, regulatory, target, symbolic, and motivational subsystems.

Keywords:

higher education, regional university, development strategy, principle.

Институт высшего профессионального образования в России находится в процессе трансформаций, связанных с необходимостью перехода к многоуровневой системе образования, фрормирующей мировое образовательное пространство. В условиях структурной модернизации высшей школы, оптимизации численности учебных заведений каждый вуз стремится сохранить конкурентоспособность и потенциал. В связи с этим актуализируется потребность в разработке и реализации программы регионализации системы высшего образования, которая позволила бы региональным учебным заведениям выбирать образовательную стратегию, соответствующую социально-экономическим, культурным, демографическим и другим особенностям территории. В предлагаемой статье делается попытка определения принципов фрормирования стратегий развития региональных вузов в контексте новых ориентиров высшего образования.

Анализ теоретических источников (трудов М.К. Горшкова, Т.М. Дадаева, И.М. Ильинского, И.В. Налетовой, М.В. Павлюткина, С.И. Плаксия, И.М. Фадеевой, Ф.Э. Шереги) [1] позволяет сделать вывод, что новые ориентиры модернизации высшего образования России связаны с изменением образовательной парадигмы, усилением роли социокультурной составляющей образовательной системы, внедрением прогрессивных методов обучения, обеспечением практической ориентированности обучения, установлением тесной взаимосвязи высшего образования с другими социальными институтами, структурными изменениями, оптимизацией сети вузовских филиалов, расширением межвузовского сотрудничества, совершенствованием международных об- 
разовательных услуг. Эти ориентиры, оставаясь базовыми для всех вузов, в том числе региональных, конкретизируются и дополняются с учетом специфики того или иного региона (содействие трудоустройству выпускников, организация стажировки на профильных предприятиях, дополнительное профессиональное образование и т. д.).

Социология вводит регион в поле анализа в качестве субъекта социального действия, который в самом общем понимании определяется как население, проживающее на определенной территории и создающее в процессе деятельности производственную, социальную и культурную инфраструктуру. Именно в территориальных общностях осуществляется обмен всеми видами социальной деятельности, которые обеспечивают воспроизводство населения. С социологической точки зрения регион как административно-территориальная единица характеризуется через деятельность субъектов, объединенных едиными связями между такими социальными институтами, как средства массовой информации, органы местного самоуправления, а также между процессами, протекающими как в хозяйственной жизни, так и в социальной. Логика исследования приводит к выделению понятия «регион присутствия вуза», которое определяется как административно-территориальная единица, имеющая вузы по подготовке специалистов и оказывающая тем самым влияние на социально-экономическое развитие региона посредством взаимодействия учебных заведений с предприятиями [2].

Новые ориентиры высшего образования становятся основой фоормирования стратегии функционирования региональных вузов. Любая стратегия, будучи обобщенной моделью долгосрочных действий, включает в себя по меньшей мере две составляющие: 1) рамочные ориентиры для осуществления долгосрочных действий; 2) направления для их реализации. Далее предпринята попытка определить рамочные ориентиры, или, иными словами, принципы создания стратегий.

1. В динамичном и быстро развивающемся мире, сложной социальной, экономической и политической ситуации современный человек должен легко адаптироваться, быстрее приобретать новые знания и навыки в широком диапазоне контекстов. Равный доступ всех слоев населения к возможностям обучения является обязательным условием реализации права на непрерывное образование. В ответ на эти потребности принцип непрерывного образования становится руководящим ориентиром развития и реформирования во всем мире. Страны, стремящиеся к формированию наукоемкого общества и конкурентоспособной экономики, как никогда озабочены необходимостью постоянного обновления знаний у граждан, повышения квалификации сотрудников, расширения возможностей профессионального развития.

2. Региональное высшее учебное учреждение - это образовательная организация, выпускающая специалистов высокой квалификации в соответствии с требованиями региональной политики. Особенностью региональных вузов является осуществление образовательной деятельности преимущественно в пределах региона расположения, при этом обучающихся готовят в основном для работы в местности присутствия вуза. Однако значение последнего состоит не только в том, чтобы быть местом подготовки специалистов; в значительной степени в его стенах студент сам участвует в научных исследованиях, приучается к самостоятельному поиску истины, а также получает первый опыт управленческой деятельности. Все это находит выражение в принципе региональных приоритетов.

3. В основу стратегии развития многих региональных вузов положены отраслевой и региональный принципы, позволяющие обеспечить более высокую привлекательность учебных заведений. Так, программа стратегического развития БГТУ им. В.Г. Шухова ориентирована на то, чтобы интегрировать подготовку и переподготовку кадров для сферы промышленности строительных материалов, координировать научно-исследовательские и проектно-конструкторские работы, совершенствовать технологии модернизации и организации предприятий не только для Белгородской области, но и для профильных отраслей экономики всех регионов России. В вузе готовят высококвалифицированных специалистов за счет генерации новых знаний, инновационных разработок. Обязательным условием его деятельности является тесная связь с компаниями региона, обеспечивающая процесс подготовки и переподготовки кадров, внедрения новаций [3].

4. Еще один важный принцип - клиентоориентированность. В секторе высшей школы во многих странах мира все чаще сталкиваются с массовым притоком потребителей образовательных услуг в вузы в связи с возрастающим спросом на высшее образование. Связанный с этой тенденцией сектор сталкивается с увеличивающейся мобильностью студентов, диверсифицированным контингентом обучаемых, неравенством в плане доступа, развитием информационных и коммуникационных инструментов, расширением автономии, повышающимися требованиями к отчетности вузов и дебатами по финансированию высшего образования.

В настоящее время новым в управлении в сфере высшего образования является диалог с потребителем образовательных услуг, который и станет основой развития высшей школы. Прозрачность деятельности региональных вузов должна сочетаться с системой независимых рейтингов учебных заведений и отдельных образовательных программ, в том числе опирающихся 
на опросы выпускников и работодателей в регионе. Контроль качества освоения компетенций, заложенных в базовом стандарте, следует дополнять независимыми от системы образования профессиональными экзаменами.

Основываясь на принципе клиентоориентированности, считаем важным выделить ведущие компоненты имиджа образовательного учреждения для различных групп потребителей образовательных услуг. Для многих из них (например, абитуриентов, их родителей и др.) значимыми, а зачастую и определяющими факторами выбора регионального вуза являются цена на образовательные услуги, а также сроки обучения. Для учителей общеобразовательных учреждений главными составляющими имиджа вуза выступают его взаимодействие со школами и связь между участниками образовательного процесса «школа - вуз».

5. Образование как область социальной сферы общества должно опережать в развитии другие формы социокультурной и экономической активности социальных субъектов экономики и культуры, особенно в их научной и инновационной деятельности. В этом заключается суть принципа опережающего развития. Поэтому наука, прежде всего фундаментальная, которая была и будет главным источником наполнения образовательного потенциала общества, сегодня не может быть оторвана от подготовки кадров и накопления интеллектуального ресурса социума.

6. Переходя к рассмотрению следующего - проблемно ориентированного - принципа, отметим, что возможные и своевременно нескорректированные дисфункции образовательной системы причиняют обществу значительный вред, который проявляется не сразу. Он аккумулируется и в итоге разрушает социальные процессы, ведет к длительной деградации общественных структур, девальвации культурной среды, резкому снижению уровня профессиональных компетенций, что в свою очередь оказывает деструктивное влияние на все остальные структурные элементы государства. В этих условиях особую важность приобретает проблемно ориентированный принцип формирования стратегии, суть которого можно выразить в следующих пунктах.

Во-первых, любая стратегия в сфере профессионального образования связана с решением того или иного вопроса. Поэтому стратегия начинается с уяснения и правильной постановки проблемы, которую нужно преодолеть. Во-вторых, характер и динамика стратегического развития определяются последовательным и поступательным движением к разрешению выявленной проблемы. В-третьих, эффеективность стратегии измеряется успешностью разрешения проблемы.

7. Продолжая анализ стратегических принципов развития регионального вуза, следует обратиться к принципу системности, соблюдение которого имеет большое значение для обеспечения оптимального функционирования как регионального вуза в целом, так и отдельных направлений его деятельности. В частности, при формировании такого компонента, как позитивный имидж вуза, данный принцип выражается в том, что для эффективного воздействия на потребителей образовательных услуг требуется целостный и непротиворечивый образ, включающий рекламное сопровождение и различные целевые акции. При этом имидж должен содержать небольшое число элементов, чтобы его сложная конструкция не мешала общему восприятию. Кроме того, немаловажной характеристикой имиджа является его реалистичность, поскольку приукрашивание достоинств снижает доверие к учебному заведению. Прагматичность, т. е. ориентированность на круг задач, соответствующих целям, вызовет у целевой группы необходимый эмоциональный отклик.

Следуя системному подходу к формированию имиджа регионального вуза, мы выделяем в нем шесть подсистем. Ценностная включает в себя основные ценности и смыслы, на которых базируются прочие имиджевые построения. C опорой на них определяется содержание образа вуза, сформулированное в виде принципов. Когнитивная подсистема проявляется в специально отобранной и иерархически организованной информации о вузе. При этом сведения для внутренних и внешних пользователей различны. Нормативная подсистема представляет собой комплекс требований, соблюдаемых работниками образовательного учреждения, участвующими в функционировании имиджа. Целевая подсистема определена набором целей и задач регионального вуза, которые он стремится достичь и выполнить соответственно. Символическая подсистема выражена комплексом символов и знаков, определяющих ценности вуза в доступной форме, позволяющих разработчикам адресовать данные о региональном вузе целевым группам потребителей. Мотивационная подсистема имиджа регионального вуза необходима для установления явных или скрытых стимулов, которые побуждают целевые группы потребителей образовательных услуг в регионе к ожидаемым реакциям.

Таким образом, успешная разработка стратегии развития регионального вуза в контексте новых ориентиров высшей школы возможна при условии реализации определенных принципов как методологических и технологических ориентиров целенаправленной деятельности. Соблюдение этих принципов обеспечивает непрерывность образования; подготовку специалистов высокой квалификации в соответствии с требованиями региональной политики; удовлетворение запросов регионов и профильных отраслей экономики в кадрах; диалог с потребителями образовательных услуг в сфере высшего образования; опережающее развитие системы высшего обра- 
зования как фрактора ускоренного прогресса региона; проблемно ориентированный подход к разработке и осуществлению стратегии развития региональных вузов; оптимальное функционирование регионального учебного заведения как системы в единстве ее подсистем.

\section{Ссылки:}

1. Дадаева Т.М., Фадеева И.М. Реформа высшей школы: парадоксы и тупики институциональных изменений // Университетское управление: практика и анализ. 2014. № 4-5 (92-93). С. 28-35 ; Ильинский И.М. «Модернизация» российского образования в контексте мировой глобализации // Знание. Понимание. Умение. 2012. № 3. С. 3-23 ; Его же. Высшее образование для XXI в. // Там же. 2012. № 4. С. 3-7 ; Модернизация российского образования: проблемы и перспективы / под ред. М.К. Горшкова, Ф.Э. Шереги. М., 2010. 352 с. ; Налетова И.В. Исследования современного высшего образования: концепт метафундаментализма : монография. Тамбов, 2005. 307 с. ; Павлюткин М.В. Организационные изменения в российских вузах: институционализация качества образования // Социология образования. 2010. № 3. С. 48-58 ; Плаксий С.И. Высшее образование: желаемое и действительное. М., 2008. 776 с. ; Шереги Ф.Э. Образование как социальный институт: функции и дисфункции // Россия реформирующаяся. 2015. № 13. С. 12-36.

2. Жирякова С.Н., Ильяева И.А. Регион как объект междисциплинарного исследования // Вестник Тамбовского университета. Сер.: Гуманитарные науки. 2010. № 4. С. 206-212.

3. Некоторые итоги реализации программы стратегического развития БГТУ им. В.Г. Шухова в 2012-2015 гг. / С.Н. Глаголев, Н.А. Шаповалов, Е.И. Евтушенко, В.М. Поляков, Е.А. Яковлев, П.И. Оспищев, Е.А. Дороганов // Формирование сети опорных региональных университетов : сборник докладов научно-методической конференции. Томск, 2015. C. 29-30.

\section{References:}

Dadaeva, TM \& Fadeeva, IM 2014, 'Higher Education Reform: Paradoxes and Deadlocks of Institutional Change', Universitetskoye upravleniye: praktika i analiz, no. 4-5 (92-93), pp. 28-35, (in Russian).

Glagolev, SN, Shapovalov, NA, Evtushenko, El, Polyakov, VM, Yakovlev, EA, Ospischev, PI \& Doroganov, EA 2015, 'Some Results of the Implementation of the Strategic Development Program of BSTU in 2012-2015', Formirovaniye seti opornykh regional'nykh universitetov: sbornik dokladov nauchno-metodicheskoy konferentsii, Tomsk, pp. 29-30, (in Russian).

Gorshkov, MK \& Sheregi, FE (eds) 2010, Modernization of Russian Education: Problems and Prospects, Moscow, 352 p., (in Russian).

llinsky, IM 2012a, 'Higher Education for the 21 ${ }^{\text {st }}$ Century', Znaniye. Ponimaniye. Umeniye, no. 4, pp. 3-7, (in Russian).

llinsky, IM 2012b, '"Modernization" of Russian Education in the Context of World Globalization', Znaniye. Ponimaniye. Umeniye, no. 3, pp. 3-23, (in Russian).

Naletova, IV 2005, Studies of Modern Higher Education: the Concept of Meta-Fundamentalism: a monograph, Tambov, 307 p., (in Russian).

Pavlyutkin, MV 2010, 'Organizational Changes in Russian Universities: the Institutionalization of the Quality of Education', Sotsiologiya obrazovaniya, no. 3, pp. 48-58, (in Russian).

Plaksiy, SI 2008, Higher Education: Desired and Valid, Moscow, 776 p., (in Russian).

Sheregi, FE 2015, 'Education as a Social Institution: Functions and Dysfunctions', Rossiya reformiruyushchayasya, no. 13, pp. 12-36, (in Russian).

Zhiryakova, SN \& Ilyaeva, IA 2010, 'The Region as a Focus of Interdisciplinary Research', Vestnik Tambovskogo universiteta. Ser.: Gumanitarnyye nauki, no. 4, pp. 206-212, (in Russian). 